\title{
A Qualitative Study Comparing the Experiences of the Meditation-Based Lifestyle Modification Program with Multi-professional Psychiatric Treatment for Female Outpatients with Mild to Moderate Depression
}

\author{
Julian Gross ${ }^{1}$, Karin Matko ${ }^{1}$, Jill Vennemann ${ }^{1}$, Holger Carl Bringmann ${ }^{2,3,}{ }^{*}$
}

1. Institute of Psychology, Chemnitz University of Technology, Chemnitz, Germany; E-Mails: grossjulian@icloud.com; karin.matko@psychologie.tu-chemnitz.de; jill.vennemann@yahoo.de

2. Institute for Social Medicine, Epidemiology and Health Economics, Charité-Universitätsmedizin, Berlin, Germany, corporate member of Freie Universität Berlin, Humboldt-Universität zu Berlin, and Berlin Institute of Health; E-Mail: holger.bringmann@charite.de

3. Department of Psychiatry, Psychosomatics and Psychotherapy, Diakoniekliniken Zschadrass, Colditz, Germany

* Correspondence: Holger Carl Bringmann; E-Mail: holger.bringmann@charite.de

Academic Editor: Peta Stapleton

Special Issue: Mind-Body Approaches that are Revolutionizing the Health Field

OBM Integrative and Complementary Medicine 2021, volume 6 , issue 4

doi:10.21926/obm.icm.2104054
Received: July 31, 2021

Accepted: November 21, 2021

Published: December 14, 2021

\begin{abstract}
Meditation-Based Lifestyle Modification (MBLM) is a complex eight-week mind-body intervention based on the traditional eight-fold path of classical yoga. MBLM was developed for mental health care, and it combines ethical living, physical yoga, and meditation. In this qualitative study, the subjectively perceived efficacy of MBLM was compared to the perceived efficacy of an individually tailored, multi-professional psychiatric treatment (MPT) in a psychiatric outpatient clinic. Twelve patients were interviewed for this study (six for each condition). All qualitative interviews were analyzed using thematic analysis. In total, five main themes with associated subthemes emerged from the data: calmness, increased awareness, interpersonal relationships, depressive symptoms, and difficulties within the therapy. Moreover, our study showed significant differences between the two therapy groups. First,
\end{abstract}

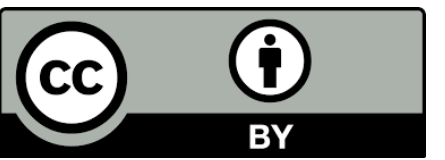


the groups differed regarding the frequency with which various topics were addressed by the patients. Second, the perceived effectiveness of both therapies (MBLM vs. MPT) varied according to descriptions of the perceived changes in each participant. The participants in the MBLM program generally appeared to experience a deeper emotional-experiential integration which contrasted with the more cognitive-behavioral processing of the MPT patients. These findings may guide further research and the implementation of similar complementary therapies in psychiatry.

\section{Keywords}

Qualitative analysis; thematic analysis; yoga; meditation; ethical living; lifestyle modification; psychiatry; depression; outpatients

\section{Introduction}

In the best-case scenario, mental health care providers meet the conditions of a guideline-based, multi-professional treatment of depression. They are then able to implement guideline-based, individually tailored therapeutic interventions based on pharmacotherapy, psychotherapy, sociotherapy, occupational therapy, and other adjunctive therapies [1]. However, in standard outpatient care, multi-professional treatment is often unavailable, and the care provided is substandard [2]. As per the projection of the World Health Organization, depression might account for the largest share of the global disease burden by 2030 [3]. Additional therapeutic options are needed, particularly those that strengthen self-efficacy and the capacity for self-care to combat depression.

In mind-body medicine, both yoga [4] and meditation [5] are simple, accessible, cost-effective, and beneficial treatments of depression. However, in modern Western perception, application, and practice, traditional yoga and philosophy are often removed from their traditional context, secularized, and reduced to their physical aspects ("yoga as exercise") [6]. The traditional forms of yoga and meditation, however, are embedded in a virtue-based philosophical and spiritual context and thus aim to holistically impact the practitioner's lifestyle [7]. Classical yoga does not focus on health and well-being but rather on the expansion of consciousness and spiritual liberation ("enlightenment") [7]. The ethical precepts, physical disciplines, and meditative practices of yoga probably acted synergistically and led to a deepening and refinement of the aspirant's practice. In particular, the ethics and virtues of yoga have seldom found their way into the contemporaneous yoga practice of Western cultures. However, virtue-based treatments have also been shown to be effective in treating depression [8, 9], and spirituality or religiosity are considered predominantly positive predictors of mental and physical health [10]. Thus, it seems plausible that a combination of meditative, physical, virtue-based, and spiritually informed therapies may positively influence the treatment of depression.

Meditation-Based Lifestyle Modification (MBLM) is a complex eight-week mind-body intervention based on the traditional eight-fold path of classical yoga [11]. It combines physical yoga, meditation practice, virtues, and spirituality. MBLM has been implemented successfully in patients with depression, demonstrating positive effects on depressive symptoms, eudaimonic well-being, 
and personal empowerment $[12,13]$. In a qualitative study [14], patients who received MBLM treatment reported increased vitality, inspiration, better orientation in life, and recognized their strengths. Thus, MBLM probably acted as an antidepressant in the context of positive psychology [15]. In particular, aspects of ethical living have been highlighted as subjectively effective factors driving positive changes [14].

However, MBLM has not yet been compared to a guideline-based, multi-professional treatment of depression. Qualitative studies are well-suited for finding new treatments and the subjective experience of patients receiving those. A qualitative comparison is performed in health research to better understand experiences and processes while demonstrating how phenomena differ between groups [16]. Therefore, in this study, we conducted qualitative interviews to compare MBLM to a multi-professional psychiatric treatment (MPT).

In this study, we compared qualitative data generated from 12 in-depth interviews of two groups of psychiatric outpatients with mild to moderate depression. One group participated in the MBLM program, while the other group received the multi-professional psychiatric care of the same outpatient clinic. To measure the long-term effects of the study, participants were interviewed twice. The purpose of this study was to better understand a) the subjective theories of the participants about perceived changes regarding the treatment (MBLM or MPT) and b) the differences of these subjective theories between the two groups.

\section{Methods}

\subsection{Design and Setting}

This study was part of a larger randomized controlled trial (ClinicalTrials.gov Identifier: NCT03652220) with $n=81$ participants that investigated the effectiveness of MBLM in depression [11]. Two phases of randomization were conducted in the parent study. Before the first phase (eight weeks), the participants were randomly assigned to one of three groups: intervention group (MBLM), control group (CONTROL), and treatment as usual (MPT). In the second phase (16 weeks), all participants previously placed in the MBLM group were assigned to MPT + MBLM and the participants in the CONTROL and MPT groups were randomly assigned to either MPT or MPT + MBLM. In this study, we focused on participants in the parent study who had either completed the eight-week MBLM program or consistently received MPT without MBLM. Participants were contacted and interviewed consecutively after the first patient in the MBLM group had the sixmonth follow-up. A total of six participants per group were interviewed. To identify any differences between short-term and long-term effects, participants were assessed at two different time points: three participants per group were interviewed immediately after the intervention (eight weeks, T1) and three participants per group were interviewed at the six-month follow-up (24 weeks, T2).

\subsection{Sample}

Patients were recruited through the outpatient clinic of the Clinic for Psychiatry, Psychosomatics, and Psychotherapy, Diakoniekliniken Zschadrass, Colditz, Germany. The attending psychiatrist informed them about the study, which was also available on a flyer in the waiting room of the outpatient clinic. All patients were at least 18 years old and had mild or moderate depression according to the ICD-10 criteria. To participate in this study, the patients were required to be able to 
perform gentle yoga exercises and sit still for $20 \mathrm{~min}$. Patients with obsessive-compulsive disorder, organic brain disease or addictions, psychotic symptoms, or acute suicidality were excluded. A total of 12 patients (all female) aged $30-64$ years (mean $=52.75 ; S D=9.51$ ) were interviewed for this study. Seven patients (58.3\%) reported recurrent episodes of depression, and one of these patients had psychiatric comorbidity (ICD-10: F40.1; social phobia). All patients had previously received several months of psychotherapy $(M=30.8 ; S D=30.5)$. Five patients previously underwent inpatient treatment, and nine patients previously performed day-clinic stays. Four patients received antidepressant medication, and two of those also received antipsychotic medication. Nine patients reported irregular yoga practice in the past, and none of the patients reported the practice of mantra meditation.

\subsection{Interventions}

The MBLM program is based on the eight-fold path of classical yoga according to Patanjali [7] and consists of three domains, which include Ethical Living, Healthy Lifestyle, and Mantra Meditation [11]. Patients participated in $8 \times 180$ min weekly group sessions and were recommended to practice yoga for $45 \mathrm{~min}$ at home every day. Each session (group session and home practice) included a variety of practices based on the three domains mentioned above. Each week, ethical recommendations related to the yoga philosophy of the yamas and niyamas were presented and discussed within the group. They included the topics of non-violence, truthfulness, non-stealing, non-excess, non-greed, purity, contentment, and transcendence. Following this group discussion, patients were instructed to follow breathing exercises and gentle yoga postures shown by the therapist. Another part of the Healthy Lifestyle domain entailed information on basic Ayurvedic lifestyle and dietary recommendations in an introductory session before the course. In the last part of each group session, all participants silently meditated with a mantra that they had chosen during the introductory session. Full details with manuals of the intervention have been published [11, 12].

Patients in the comparison group (multi-professional standard care for psychiatric outpatients) received an individually tailored program of different therapy components, including psychotherapy/psychoeducational therapy, movement and sports therapies, relaxation therapy, and occupational therapy; for further details, see Table S1 in the supplementary material. Therapies were administered by specifically trained psychiatrists, nurses, occupational therapists, movement therapists, art therapists, and social workers.

\subsection{Data Collection}

Based on the concept of episodic interviews [17] and the subjective perception of the participants in a previous feasibility study [12], an interview guideline was consensually developed by the research team and used for the qualitative semi-structured interviews in this study. The interview guideline (for details, see Table $\mathrm{S} 2$ in the supplementary materials) focused on the following topics: general changes in daily life, change in depressive symptoms, the experience of the therapy received, and spirituality. The interviews were conducted through a casual conversation. However, all the topics of the interview guideline were discussed in each interview. JG conducted all the interviews. The interviews were recorded and subsequently transcribed by JG. For consensus among the researchers [18], all transcripts and analyses were reviewed for objective fit by JV in a peer review process [19]. 


\subsection{Data Analysis}

To analyze the data, we conducted a thematic analysis [18], which comprised six phases. In the first phase, a transcript of the interview was created. Transcription establishes a familiarization with the material [20], and thus, it is a key phase of qualitative research [21]. In the second phase, the transcripts were read several times, and notes were taken to guide the following examination in greater detail. In this process, initial codes were assigned as comprehensively as possible and formulated close to the transcribed content to precisely map the respective segment of the raw data related to the research question [22]. After an analysis of the entire dataset, recurring motifs were identified based on the codes created. In the third phase, main themes and subthemes were formed from the previously created codes. In the fourth phase, the main themes and subthemes were revised and refined according to the entire dataset. In the fifth phase, the extracted themes were named. The report of the results (sixth phase) made the complex contents of the data understandable by finding and giving meaningful examples. Furthermore, we calculated the number of assigned codes in each group to compare the themes quantitatively between the groups.

We used the software f4analyse (version 2.5.4.0) to process and analyze the transcripts. Following the consensual approach, the transcription and the analysis of all interviews were peerreviewed [19] (by JG and JV) to remove potential confirmation bias and increase inter-coder reliability. The analysis was supervised by $\mathrm{KM}$, an experienced researcher.

\section{Results}

The thematic analysis of all interviews resulted in five main themes (Figure 1): calmness, increased awareness, interpersonal relationships, depressive symptoms, and difficulties within the therapy. All the themes were subdivided into subthemes (Figure 1). All the themes and their corresponding subthemes are reported consecutively. Within each subtheme, results are first presented for patients who received MBLM and second for patients who received MPT. The total frequency of responses within each group and subtheme are shown in Table 1. Additional examples for each theme are presented in the supplemental data (Table S3). 

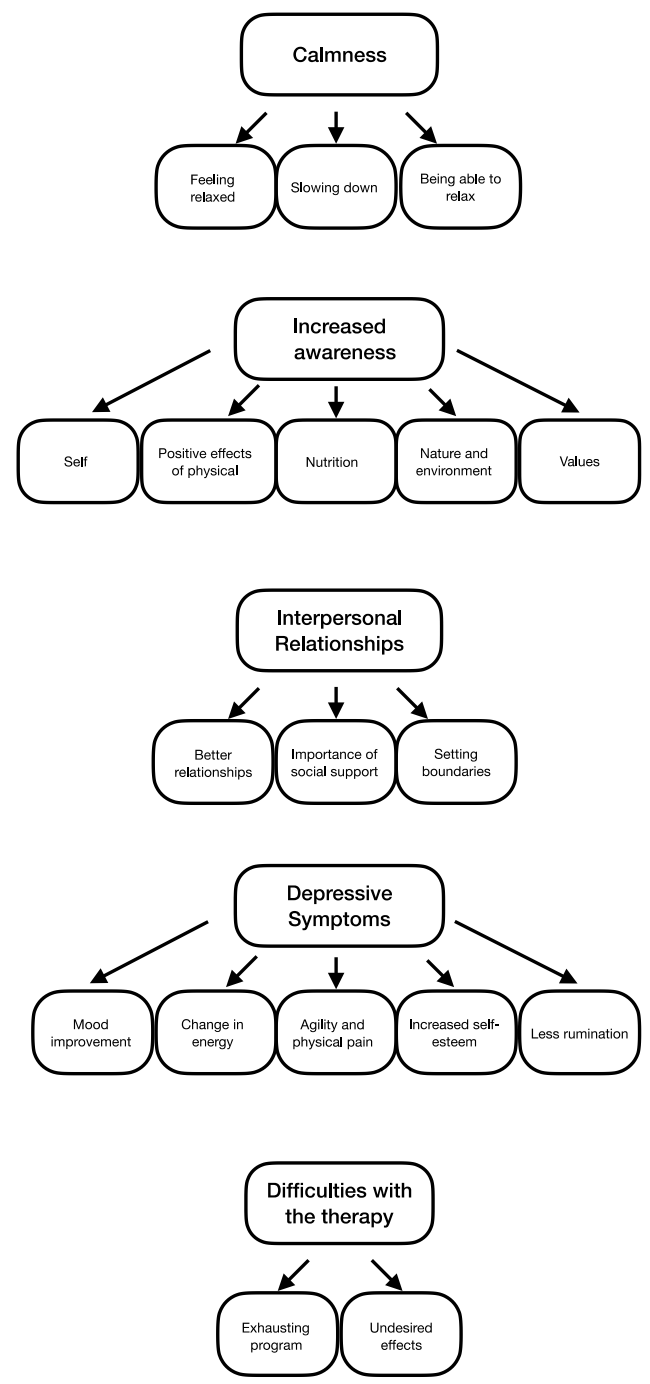

Figure 1 Five themes (upper row) and the corresponding subthemes (lower row).

Table 1 Differences in the frequency of (sub) themes between MBLM and MPT.

\begin{tabular}{lllllll}
\hline & & \multicolumn{2}{c}{ MBLM } & \multicolumn{3}{c}{ MPT } \\
Theme & Subtheme & $\mathrm{n}$ & $\mathrm{s}$ & $\mathrm{n}$ & $\mathrm{s}$ & s total \\
\hline Calmness & & 6 & 37 & 6 & 29 & 66 \\
& Feeling relaxed & 5 & 18 & 6 & 11 & 29 \\
& Slowing down & 6 & 19 & 4 & 4 & 23 \\
& Being able to relax & 0 & 0 & 6 & 14 & 14 \\
Increased & & 6 & 30 & 4 & 21 & 51 \\
awareness & & 6 & 20 & 4 & 11 & 31
\end{tabular}




\begin{tabular}{lrrrrr}
$\begin{array}{l}\text { Positive effects } \\
\text { physical activity }\end{array}$ & \multicolumn{1}{c}{ of } & 4 & 3 & 7 & 11 \\
$\begin{array}{l}\text { Nutrition } \\
\begin{array}{l}\text { Nature } \\
\text { environment }\end{array}\end{array}$ & 2 & 2 & 2 & 2 & 4 \\
and & 4 & 4 & 1 & 1 & 5 \\
alues & 6 & 43 & 0 & 0 & 43
\end{tabular}

Interpersonal relationships

\section{6}

20

6

34

54

\begin{tabular}{|c|c|c|c|c|c|c|}
\hline & Better relationships & 3 & 4 & 1 & 4 & 8 \\
\hline & $\begin{array}{l}\text { Importance of social } \\
\text { support }\end{array}$ & 5 & 10 & 6 & 16 & 26 \\
\hline & Setting boundaries & 6 & 6 & 6 & 14 & 20 \\
\hline \multirow[t]{6}{*}{$\begin{array}{l}\text { Depressive } \\
\text { symptoms }\end{array}$} & & 6 & 59 & 6 & 51 & 110 \\
\hline & Mood improvement & 6 & 26 & 5 & 9 & 35 \\
\hline & Change in energy & 5 & 7 & 6 & 21 & 28 \\
\hline & Agility and physical pain & 5 & 9 & 2 & 2 & 11 \\
\hline & Increased self-esteem & 3 & 5 & 4 & 6 & 11 \\
\hline & Less rumination & 6 & 11 & 6 & 14 & 25 \\
\hline \multirow[t]{3}{*}{$\begin{array}{l}\text { Difficulties with } \\
\text { the therapy }\end{array}$} & & 1 & 1 & 5 & 5 & 6 \\
\hline & Exhausting program & 1 & 1 & 0 & 0 & 1 \\
\hline & Undesired effects & 0 & 0 & 5 & 5 & 5 \\
\hline
\end{tabular}

\subsection{Calmness}

This theme was relevant for all patients of both groups. The participants reported increased calmness as a result of general relaxation and slowing down in daily life by applying relaxation techniques. MBLM participants predominantly reported fewer action-oriented changes and reported feeling more relaxed in general, whereas patients in the MPT group were more likely to comment on action-oriented issues. 


\subsubsection{Feeling Relaxed}

Patients from the MBLM group reported being more relaxed as they were able to distance themselves from their expectations:

"I was so narrow-minded before. Everything really had to go according to plan for me. I no longer do that." (30 years old, MBLM)

Patients reported being more relaxed in situations that would have upset them before:

"I can look past it, which I never could before, really never." (63 years old, MBLM)

Patients in the MPT group became more relaxed by being aware of dysfunctional behaviors:

"I became more aware of my role, which I have burdened myself with. To make everything more than perfect and to accomplish everything more than necessary [...] but that was too extreme. That has also taken so much energy from me all the way around." (46 years old, MPT)

Additionally, they mentioned the possibility of distancing themselves from these behaviors after therapy:

"That at least I recognize and catch that and start accepting things differently than before." (40 years old, MPT)

Or to split tasks into smaller parts and perform them later:

"I do what I have to do in a day. But I portion it out for myself. And what I can shift, I also shift sometimes, that's okay" ( 55 years old, MPT)

Often, they reported conversing with themselves, apparently to gain awareness through an inner dialogue:

"'Leave it now, do it later"; "It's not so much of a tragedy"; "... so that works much better now." (57 years old, MPT)

\subsubsection{Slowing Down}

In this subtheme, the patients from the MBLM group stated that they felt calmer overall and that they discovered the positive effects of slowing down in everyday life:

"I realize that when I do things peacefully, they are just much more relaxed and effective." (64 years old, MBLM)

They reported the impression of having more time:

"And I can start the day much more calmly. I can take my time for everything. Um, things that I do, to just do them better, yes." (55 years old, MBLM)

And, as a result, having a better focus on their needs and feelings:

"Slowing down, um, focusing on my needs and sensitivities and also my inner 'construction sites'." (61 years old, MBLM)

They also spoke about meditation which helped them to feel relaxed:

"Meditation is just really, um, how to say, a quiet place in my inner self." (30 years old, MBLM)

Patients in the MPT group also felt calmer overall:

"I have become, let's say, calmer overall, right?" (57 years old, MPT)

Some patients were more likely to feel calmer by interacting with the environment, where they could relax mentally:

"And there I can also feel such a (exhales), how should I say, a connection to nature. And I say all this hustle and bustle which I actually do not like at all in today's life; to leave that behind a little bit, 
at least for the moment, when you say, "Oh in the forest, fresh air, the birds are chirping, there are still rays of sunshine coming through somewhere.'" (46 years old, MPT)

\subsubsection{Being able to relax}

The patients in the MPT group learned techniques in therapy that helped them to relax:

"That we have learned certain techniques and how to deal with it. And when I realize, "Now I'm stressing out again" I try to apply that in different places and calm myself down before I've even really ramped up." (55 years old, MPT)

Progressive muscle relaxation, according to Jacobsen [23], was repeatedly experienced as helpful in this context:

"Because you have to be very focused then, you have to tighten your hands and your shoulders and so on. And that is more relaxing for me." (46 years old, MPT)

To initially perform these techniques, patients had to be aware of the need to relax. Accordingly, patients almost always mentioned their increased awareness of stress or inner tension:

"If I then noticed that I was getting all tense again or had any tension, I took a short sequence at home where I did a few exercises and then things continued in a completely different way." (55 years old, MPT)

\subsection{Increased Awareness}

Patients in the MBLM group reported changes mainly in the areas of self and virtue, while patients in the MPT group were more likely to apply to themselves the knowledge acquired in therapy.

\subsubsection{Self}

Patients in the MBLM group reported having gained an increased awareness of their previous lifestyle and self:

"Throughout the discussions, it all surfaced, and I became aware of what I had done to myself over the years. Done to myself. I have been stealing from myself (...), from my own (...) humorous nature. I have actually stolen from myself my laughter. My self-esteem, my courage." (63 years old, MBLM)

Furthermore, the patients in the MBLM group also reflected upon the differences in them before and after therapy:

"That I actually know myself as a funny person and as someone who can handle it and who gets it together and [before the therapy] had the feeling "I cannot do that anymore." But it's different now, I realize right now that I'm becoming exactly me again." (64 years old, MBLM)

Patients in the MPT group were more likely to give explanations about themselves derived from the therapies instead of an experience:

"So that's also how it is now as a result of the therapy, especially through stress management, that I have noticed: I myself am the factor that stresses me out and that I can also change that." (55 years old, MPT) 


\subsubsection{Positive Effects of Physical Activity}

All patients in the MBLM group reported a beneficial effect of yoga:

"For me, yoga is more for the body, this stretching. That is good." (30 years old, MBLM)

Often, they did not indicate a specific effect of yoga but described that the practice was generally good for them:

"It is incredibly good for me to spend time with myself and with these things." (64 years old, MBLM)

Similar to the patients in the MBLM group, the majority of the MPT patients also reported a nonspecific positive effect of physical activity. However, they did not only refer to yoga but also different possibilities of activities:

"So I've really taken that on, walking three to four times a week on my own, with the walking stick. That helps me a lot." (57 years old, MPT)

\subsubsection{Nutrition}

The patients in the MBLM group noticed a change in their diet:

"What I'm cutting out more now is sugar. Sugar is really like an extreme addiction. And now I can gradually cope better without it again." (30 years old, MBLM)

The MPT patients were more likely to report resolutions to eat differently:

"Not everything is successful yet, especially with concentrated eating. Yes, that's what you do (laughs), and you sometimes think about it, but then you have another thought in your head again." (50 years old, MPT)

The reports of the two groups differed in their focus: the MBLM group addressed changes that had already taken place, and the MPT group addressed changes that were being pursued.

\subsubsection{Nature and Environment}

The patients in the MBLM group emphasized that they had discovered a greater awareness of nature:

"And I also live more consciously. And more grateful also in terms of nature. And things that I can learn from nature." (55 years old, MBLM)

One patient in the MPT group expressed a similar experience. In contrast to the MBLM group, however, her description was more of a resolution than a change that had already occurred:

"And then also, I do not know, when you're out in nature or something, you stop and say, "Oh, I'm going to take a look at that, let it have an effect on you [...]. Interviewer: And you put that into practice in everyday life? Participant: I try." (50 years old, MPT)

\subsubsection{Values}

The comments on this subtheme were identified for the values of the MBLM course. The MBLM patients commented on all twelve topics of life ethics. On the topic of non-violence, the patients expressed a wish for a harmonious world:

"These mantras all point to this: non-violence. And if all (the) people would do something like that, (they) would live non-violently; there would be no more wars." (55 years old, MBLM) 
The patients experienced ethical issues in their everyday lives and included them in their narratives as a natural part of their lives:

"Not holding on, i.e., letting go. That was the topic when my little son [...] knocked out his teeth in this Bobby-Car accident, and I consciously told myself before the meditation that I will now let go of these feelings because they really pulled me down. [...] And to apply that during meditation, to consciously let go of these feelings; that created a relief." (30 years old, MBLM)

Additionally, they also reported consciously integrating topics into meditation to be able to process them more deeply:

"And then also that every week I pick a topic that I integrate into meditation." (64 years old, MBLM)

Furthermore, they were able to realize the relevance of the topics in different contexts:

"Not stealing is actually not just thinking about someone taking something from you, but the whole emotional thing. That has impressed me quite deeply." (64 years old, MBLM)

\subsection{Interpersonal Relationships}

Patients in both groups expressed an improvement in relationships due to an increase in honesty. Furthermore, they emphasized the need to set boundaries and pointed out the relevance of social support.

\subsubsection{Better Relationships}

Patients in the MBLM group attributed the improvement in the relationship to talking things out or being more honest in a relationship:

"We have also talked about it and he, he also calls me when he has difficulties now, also with my ex-husband." (63 years old, MBLM)

From the MPT group, only one patient commented on this subtopic. But she also attributed the improvement in the relationship to more honesty in the relationship:

"He (my partner) likes to give you tasks and thinks he has to keep you busy. Then I say, 'You have a lot more free time, so you do that if you want to.' He does not handle it well, but he learns that maybe it's true after all. I do not want to be his employee. And to say this again very consciously." (40 years old, MPT)

\subsubsection{Importance of Social Support}

The patients in the MBLM group frequently mentioned contacts that provided security and understanding and were perceived as important:

"But I get support here, I can always ask questions, so the therapists are always open to everything I ask. [...] So I felt very safe and accepted by both of them." (55 years old, MBLM)

The patients in the MPT group, on the other hand, focused more on the feeling of not being alone with their illness:

"Hearing from other patients how they have been, that almost brings me more than a one-onone conversation, oddly enough. Because I say to myself, "You're not alone, others have problems like that too.'" (57 years old, MPT) 


\subsubsection{Setting Boundaries}

The patients in the MBLM group described being more aware of their limits:

"So many people come to me now, so many. First of all, (those) who have not been in touch for ages, where I also look and am careful and tell myself, 'Boundaries'. What do you want now, or what does he want from you now. Are you willing to give that now? Or is that something you do not want to (give) right now?"' (64 years old, MBLM)

The patients in the MPT group described having consciously introduced goals or wanting to be better able to do so in the future:

"To finally build up this self-mechanism to say "Nah, stop. You all want too much from me right now." (40 years old, MPT)

\subsection{Depressive Symptoms}

Patients reported an increase in energy and improved self-esteem. Patients in the MBLM group mentioned yoga and its positive effect on agility, physical awareness, and the reduction of physical pain. Furthermore, they noticed less rumination, while patients in the MPT group were more likely to actively do something about their rumination. They more often stated that they had noticed a change in energy.

\subsubsection{Mood Improvement}

Patients in the MBLM group reported a more positive mood and higher resilience:

"That I am definitely more resilient again. I was not before, so, I'm happier again, I can participate in life again." (30 years old, MBLM)

They also mentioned a positive effect of meditation, which was often perceived as good

"Meditation ... I will continue to do that, um, yes, because I notice that it is good for me." (55 years old, MBLM).

Meditation also helped them to relieve anxious feelings or frustration:

"So that scares me that I then get into the hustle and bustle. To take myself completely out of it and say, "Now is the point, you drop everything, now you meditate for a while". [...] And then I take myself out of it, and then I come to rest. And that's where meditation helps me." (61 years old, MBLM)

Patients in the MPT group reported intentionally generating a positive mood mainly through exercise:

"Well, simply that it [doing sports] makes you happier." (55 years old, MPT)

\subsubsection{Change in Energy}

Patients in the MBLM group described an increase in energy but mostly did not cite a source:

"This time, I had so little energy for such a long time, and that was a big burden to me. That nothing was finished or went much slower, and now, it's slowly coming back. Now I also have more energy again, and somehow you deal with things in a completely different way." (64 years old, MBLM)

A few patients in the MPT group reported a lack of energy: 
"Because then (at the end of the day) I'm simply exhausted. Having enough energy or vitality, to go through the whole day from morning to evening, I am not there yet." (55 years old, MPT)

Most of them reported that they experienced an increase in energy, especially related to sports:

"But then I also try to remember to do Nordic Walking again. [...] I notice, with something like that, that's also my instrument on gray days, [...] And then I say (exhales): 'Never mind, now you go out.'" (46 years old, MPT).

\subsubsection{Agility and Physical Pain}

All the patients in the MBLM group described that yoga helped them to feel or perceive the body better:

"Yes, my body perception through yoga is different from before (laughs). So you feel your body more clearly. You are simply more aware of yourself." (55 years old, MBLM)

Patients also reported that performing yoga reduced their physical pain:

"And through yoga, this can be solved slowly, little by little. Yes, blockages all over the body, pains." (55 years old, MBLM)

Of the patients in the MPT group, only one patient reported having reduced pain through a specific component of therapy:

"Okay, well, through acupuncture, I do have less pain." (50 years old, MPT)

\subsubsection{Increased Self-esteem}

Patients in the MBLM group reported that they observed increased self-confidence. However, they did not comment on how the change occurred:

"Yes, you are ..., well, you have indeed become more self-confident." (55 years old, MBLM)

Patients in the MPT group had higher self-esteem after physical activities:

"So, when I come out of Pilates, I actually think, "Cool, you've dedicated an hour just for yourself, and it was fun. The exercise that, maybe, did not work out so well two weeks ago; it has worked out now." So that also strengthens my self-confidence a bit, I feel." (55 years old, MPT)

For two patients in the MPT group, an increase in self-esteem was a future goal:

"No, just really this confidence, yes just this self-confidence and also this self-reflection [...], I would like to learn that." (40 years old, MPT)

\subsubsection{Less Rumination}

The patients in the MBLM group described noticing when they lapsed into rumination:

"No, now your mind is playing its crazy little game again, and now you just cannot get it at all. Now you're jumping from A to B again. And then I take myself out, and then, I come to rest." (64 years old, MBLM)

The mantra helped them to let go of thoughts:

"The mantra is on the windshield in the car, and the thoughts are on the side [window], they pass by [like a landcape passing by while sitting in the car]." (61 years old, MBLM)

They could also end rumination through yoga exercises:

"I've done yoga three times this week, so I feel like that relaxes me and gets me out of my crazy mind." (64 years old, MBLM) 
The statements of the patients in the MPT group were more often characterized by an intentional impulse to act. They described actively "pushing away" the thoughts:

"For example, by consciously trying to push thoughts away in the evening." (55 years old, MPT)

They also used sports for the same purpose:

"No, but the exercise, um, the body has to work, and at that moment the brain is gone, one is, um, practically tuned to the physical body and, um, that's how it works. And that lasts for quite a while afterward." (46 years old, MPT)

\subsection{Difficulties in Therapy}

Despite the low number of statements on this topic, two subthemes were established.

\subsubsection{Exhausting Program}

Only one patient of the MBLM group commented on this sub-topic. She described that the therapy program made her think about things, and she found it exhausting:

"At home, you also go through (...) the topics or what happened. I mean, the drawers are partially opened again (laughs). The intensive thinking about "what did you do wrong", "what do you want to change" that is already (...) that is quite intense sometimes, yes." (55 years old, MBLM)

\subsubsection{Undesired Effects}

Five patients in the MPT group named individual therapy modules with which they had difficulties. Often this involved worsening of symptoms:

"The imaginary journey, I have now also tried to do that at home, and there I had no interest at all because the problem with me is that I become too sluggish. So, an imaginary journey makes me even more sluggish, I do not want that." (57 years old, MPT)

They also reported being overwhelmed by or unable to engage with some therapies and therefore not able to perceive their effects:

"Well, I am not yet so far that I can now, for example, um, do this role-playing [in social skills training]." (55 years old, MPT)

\section{Summary}

In summary, five overarching themes were identified for both groups reflecting subjective theories about perceived changes in their respective therapy. However, we observed a different distribution of response frequencies in various subthemes. Additionally, the two groups also differed in their reported approaches or strategies that they applied to achieve these changes.

Regarding the main theme of calmness, the patients in both groups described themselves as being calmer after therapy. The patients in the MBLM group reported feeling calmer and taking more time to relax, while the patients in the MPT group reported a more active way to relax.

Regarding the main theme of increased awareness, patients in both groups described that they became more aware of various aspects in their daily perception. MBLM participants compared themselves before and after therapy, and they were able to consciously perceive, feel, and report differences. They also attributed great importance to the values conveyed in therapy. Participants in the MPT group used a more cognitive-behavioral language to describe changes in themselves. 
They reported actively applying knowledge acquired in therapy that they used to reach individual goals by certain means. Thus, MPT participants expressed changes more mechanistically, while MBLM participants tended to embody the changes they reported on.

Patients in both groups were able to significantly reduce their depressive symptoms. MBLM patients perceived a general improvement in mood and change in energy, and they indicated that meditation and yoga enhanced their well-being in general. They were more likely to notice rumination and reported that mantra meditation and yoga helped them to stop it more quickly. However, the patients in the MPT group reported that they had primarily experienced a better mood and increased self-confidence through physical exercise. Besides sports, actively pushing away negative thoughts also helped them against rumination.

Finally, no patient in the MBLM group reported difficulties with the therapy program, while some MPT patients described problems with individual modules.

In the previous study, the distinction between the two measurement time points (T1 \& T2) was not discussed in detail, as no effect was found on the emergence of the themes. Also, the variations in the expression of perceived differences were unaltered throughout the study. Finally, the difference in the experience or processing of the therapies (deeper emotional-experiential integration of MBLM vs. cognitive-behavioral processing of MPT) also appeared unaffected by the measurement time points.

\section{Discussion}

In this study, we compared the subjective experiences of patients participating in the MBLM program with patients receiving standard care at a psychiatric outpatient clinic. Twelve in-depth interviews were conducted, and qualitative data were examined using thematic analysis. We identified five main themes with which patients from both groups described therapeutic processes and effects and found considerable differences between both groups.

Interestingly, patients in the MBLM program generally experienced a deeper emotionalexperiential integration which contrasted with the more cognitive-behavioral mode of internal processing of MPT patients. This deeper emotional-experiential integration seemed to be accompanied by a general sense of relaxation in the MBLM patients. This finding is in line with the fundamental idea of classical yoga in the yoga sutras, in which, the calming of the mind is described as the main mechanism and goal of yoga (and meditation) [7]. Also, in a qualitative study on MBLM, a stronger feeling of calmness through mantra meditation was reported [14].

Regarding the second main theme of increased awareness, the patients of MBLM commented especially on the subthemes of self and value. From the interviews of the patients in the MBLM group, it became apparent that dealing with the ethical topics of the program and reflecting on a person's behavior and relationships frequently led to new insights. These insights can be deepened with meditation and ultimately lead to more conscious life. This corresponds to findings of positive psychology, in which reflecting on one's life and resources enables a person to develop new possibilities of action that are conducive to good health and a change in the person's values [15]. Also, the improvement in mood primarily of MBLM patients through yoga and meditation has been reported in previous studies for both healthy subjects [24] and patients with depression [25-27]. Moreover, the importance of support from social relationships, which was indicated by both groups 
under the subtheme of "importance of social support", is another well-known factor in combating depression [28].

In contrast to the deeper emotional-experiential integration found in the patients of the MBLM group, the cognitive-behavioral mode of operation seen in the patients of the MPT group might be related to learning new ways of thinking and acting. This could be potentially attributed to a difference in the activation of neuropsychological bottom-up and top-down processes elicited by the two interventions (MBLM and MPT). Classical yoga, including all four components, elicits an integration of bottom-up and top-down processing on physiological, cognitive, and behavioral levels, which leads to improvements in self-regulation, embodiment, and resilience [29]. In particular, practicing yoga and meditation daily can stimulate sub-cognitive bottom-up processes and lead to multidimensional integration and embodiment [29]. As MBLM incorporates all the main aspects of classical yoga, this model could explain the emotional-experiential integration observed in the MBLM patients.

However, in the more behavioral and cognitive approach of MPT, symptom relief is primarily sought through changes in cognitive and behavioral patterns [30]. The perceptions and reports of changes in the patients were ostensibly related to newly acquired cognitive techniques and functional ways of acting and thinking. Thus, top-down processes and lower levels of integration might be predominant in the MPT group, at least in the first eight weeks. Interestingly, the positive effect of exercise dominates the reports of MPT patients on depressive symptoms. This effect was found in previous studies and is a predominantly bottom-up process [31]. Thus, depression treatment is particularly beneficial when top-down and bottom-up processes are integrated. Mindbody treatments, such as MBLM, might foster the integration and the development of body awareness and skills to regulate emotions. Yoga can target and enhance these processes [32]. This makes it highly relevant for the prevention and treatment of mental health conditions as deficits or problems in the regulation of emotion, body awareness, and a sense of self are negative predictors of various forms of psychopathology [33, 34].

This study has some limitations. The sample consisted exclusively of female participants. Although women are statistically more likely to suffer from depressive disorders [35], it would be important to interview a sufficient number of male subjects in future studies. This would allow to derive gender-specific subjective theories of the effectiveness of the program and develop gendersensitive measures. Future studies should include subjects of different age groups since most patients in our study were 30 years or older.

Another potential limitation of this study results from the complexity of the therapy programs. The MPT therapy was designed and delivered according to the individual needs of the participants, which resulted in providing different types of therapy within the MPT group. In a small sample size with high between-subject differences, a comparison of the two therapy groups might not be generalizable. Additionally, daily practice of yoga and meditation at home was highly recommended in the MBLM group, whereas the therapies of the MPT group did not systematically implement a comparable home practice. Therefore, future studies should investigate the potential influence of the differences in the intensity of therapy.

Additionally, patients in the MPT group were promised to participate in the MBLM program at the end of the study period. They reported sporadically that their expectations regarding this issue might have influenced their perceived changes in therapy positively or negatively. Furthermore, the setting might have influenced the results; MPT therapy was conducted in individual rooms, whereas 
MBLM was conducted in a single large room. Only in the MBLM group, the patients sang together at the beginning and had a small tea break in the middle of the course. A positive expectation of the success of therapy, which might be influenced by conditions of the setting [36], is considered one of the main factors of efficacy in psychotherapy [37]. In addition to the setting, the charisma of the therapists, which was often emphasized in the interviews, might have also had a positive influence on the participants. This influence could have been strengthened by the unconventional and, in comparison to the MPT modules, unique situation that the therapists appeared as a married couple and came close to the subject through the practice of yoga and meditation. Consequently, an additional influence through the intrinsic motivation of the therapists might have played a positive role.

In summary, we found subjectively perceived differences in the effectiveness of the two therapy programs. The differences were found in the different weighting of topics mentioned by each group and in the different modes of internal processing observed in the participants. Our results illustrated that participants in the MBLM program experienced deeper emotional-experiential integration compared to a more cognitive-behavioral mode of processing found in MPT patients. These findings are relevant to the individual application of complementary therapies in psychiatry but require further research.

\section{Acknowledgments}

We thank Peter Sedlmeier for his valuable feedback during the process of qualitative data analysis.

\section{Additional Materials}

The following additional materials are uploaded at the page of this paper.

1. Table S1: Description of "treatment as usual" (TAU).

2. Table S2: Interview guidelines.

3. Table S3: Additional example statements.

\section{Author Contributions}

HCB conceptualized and designed the study. JV, JG were in involved in the acquisition of data. KM supervised the data analysis. JV, JG, HCB and KM contributed to qualitative analysis and reporting. JG and HCB wrote the first draft of the manuscript. All authors worked on the final version of the manuscript.

\section{Funding}

This project was funded by Karl and Veronica Carstens Foundation under Award Numbers KVC 0/098/2018.

\section{Competing Interests}

The authors have declared that no competing interests exist. 


\section{References}

1. Gelenberg AJ. A review of the current guidelines for depression treatment. J Clin Psychiatry. 2010; 71: e15.

2. Wittchen HU, Jacobi F, Rehm J, Gustavsson A, Svensson M, Jönsson B, et al. The size and burden of mental disorders and other disorders of the brain in Europe 2010. Eur Neuropsychopharmacol. 2011; 21: 655-679.

3. World Federation For Mental Health. Depression: A global crisis. In: World Mental Health Day. Kingston: World Federation For Mental Health; 2012.

4. Klatte R, Pabst S, Beelmann A, Rosendahl J. The efficacy of body-oriented yoga in mental disorders: A systematic review and meta-analysis. Deutsch Ärztebl Int. 2016; 113: 195-202.

5. Goyal M, Singh S, Sibinga EM, Gould NF, Rowland-Seymour A, Sharma R, et al. Meditation programs for psychological stress and well-being: A systematic review and meta-analysis. JAMA Intern Med. 2014; 174: 357-368.

6. Mora JL, Berry J, Salen P. The yoga industry: A conscious luxury experience in the transformation economy. Luxury. 2018; 5: 173-196.

7. Bryant EF. The yoga sutras of patañjali: A new edition, translation, and commentary. Berkeley: North Point Press; 2015.

8. Jankowski PJ, Sandage SJ, Bell CA, Davis DE, Porter E, Jessen M, et al. Virtue, flourishing, and positive psychology in psychotherapy: An overview and research prospectus. Psychotherapy. 2020; 57: 291-309.

9. Ruini C. Positive psychology and clinical psychology: Common philosophical backgrounds, early contributors, and possible integrations. In: Positive psychology in the clinical domains. Cham: Springer International Publishing; 2017. pp.3-29.

10. Koenig HG. Religion, spirituality, and health: A review and update. Adv Mind Body Med. 2015; 29: 19-26.

11. Bringmann HC, Bringmann N, Jeitler M, Brunnhuber S, Michalsen A, Sedlmeier P. Meditationbased lifestyle modification: Development of an integrative mind-body program for mental health and human flourishing. Complement Med Res. 2021; 28: 252-262.

12. Bringmann HC, Bringmann N, Jeitler M, Brunnhuber S, Michalsen A, Sedlmeier P. Meditation Based Lifestyle Modification (MBLM) in outpatients with mild to moderate depression: A mixedmethods feasibility study. Complement Ther Med. 2021; 56: 102598.

13. Matko K, Sedlmeier P, Bringmann HC. What makes yoga effective? Differential effects of ethical education, physical yoga, and mantra meditation on well-being and stress. PsyArXiv. 2021. doi:10.3389/fpsyg.2021.672301.

14. Bringmann HC, Vennemann J, Gross J, Matko K, Sedlmeier P. "To be finally at peace with myself": A qualitative study reflecting experiences of the meditation-based lifestyle modification program in mild-to-moderate depression. J Altern Complement Med. 2021; 27: 786-795.

15. Sin NL, Lyubomirsky S. Enhancing well-being and alleviating depressive symptoms with positive psychology interventions: A practice-friendly meta-analysis. J Clin Psychol. 2009; 65: 467-487.

16. Lindsay S. Five approaches to qualitative comparison groups in health research: A scoping review. Qual Health Res. 2019; 29: 455-468.

17. Flick U. An introduction to qualitative research. 5th ed. Thousand Oaks: SAGE Publications Ltd; 2018. 
18. Braun V, Clarke V. Using thematic analysis in psychology. Qual Res Psychol. 2006; 3: 77-101.

19. Creswell JW. Qualitative inquiry and research design: Choosing among five approaches. Thousand Oaks: Sage; 2007.

20. Riessman CK. Narrative analysis. Thousand Oaks: Sage; 1993.

21. Bird CM. How I stopped dreading and learned to love transcription. Qual Inq. 2005; 11: 226-248.

22. Boyzatis RE. Transforming qualitative information: Thematic analysis and code development. Thousand Oaks: Sage; 1998.

23. Jacobson E. Progressive relaxation. Am J Psychol. 1987; 100: 522-537.

24. Sedlmeier P, Eberth J, Schwarz M, Zimmermann D, Haarig F, Jaeger S, et al. The psychological effects of meditation: A meta-analysis. Psychol Bull. 2012; 138: 1139-1171.

25. Bringmann HC. Mantra meditation in major depression: A randomized controlled trial [Internet]. Colditz: University Hospital Dresden; 2021. Available from: https://clinicaltrials.gov/ct2/show/NCT03004430.

26. Pascoe MC, Thompson DR, Ski CF. Yoga, mindfulness-based stress reduction and stress-related physiological measures: A meta-analysis. Psychoneuroendocrinology. 2017; 86: 152-168.

27. Cramer H, Ward L, Saper R, Fishbein D, Dobos G, Lauche R. The safety of yoga: A systematic review and meta-analysis of randomized controlled trials. Am J Epidemiol. 2015; 182: 281-293.

28. Cuijpers P, Geraedts AS, van Oppen P, Andersson G, Markowitz JC, van Straten A. Interpersonal psychotherapy for depression: A meta-analysis. Am J Psychiatry. 2011; 168: 581-592.

29. Gard T, Noggle JJ, Park CL, Vago DR, Wilson A. Potential self-regulatory mechanisms of yoga for psychological health. Front Hum Neurosci. 2014; 8: 770.

30. Hofmann SG, Asnaani A, Vonk IJ, Sawyer AT, Fang A. The efficacy of cognitive behavioral therapy: A review of meta-analyses. Cognit Ther Res. 2012; 36: 427-440.

31. North TC, McCullagh PE, Tran ZV, Lavallee DE, Williams JM, Jones MV, et al. Effect of exercise on depression. In: Key studies in sport and exercise psychology. London: Open University Press; 2008. pp.258-284.

32. Cox AE, Tylka TL. A conceptual model describing mechanisms for how yoga practice may support positive embodiment. Eat Disord. 2020; 28: 376-399.

33. Fuchs T, Schlimme JE. Embodiment and psychopathology: A phenomenological perspective. Curr Opin Psychiatry. 2009; 22: 570-575.

34. Gross JJ, Muñoz RF. Emotion regulation and mental health. Clin Psychol. 1995; 2: 151-164.

35. Kessler RC. Epidemiology of women and depression. J Affect Disord. 2003; 74: 5-13.

36. Burlingame GM, Fuhriman A, Mosier J. The differential effectiveness of group psychotherapy: $A$ meta-analytic perspective. Group Dyn. 2003; 7: 3-12.

37. Pfammatter $M$, Junghan UM, Tschacher W. Common factors of psychotherapy: Concepts, contradictions and a synthesis. Psychotherapie. 2012; 17: 17-31. 
OBM Integrative and Complementary Medicine 2021; 6(4), doi:10.21926/obm.icm.2104054

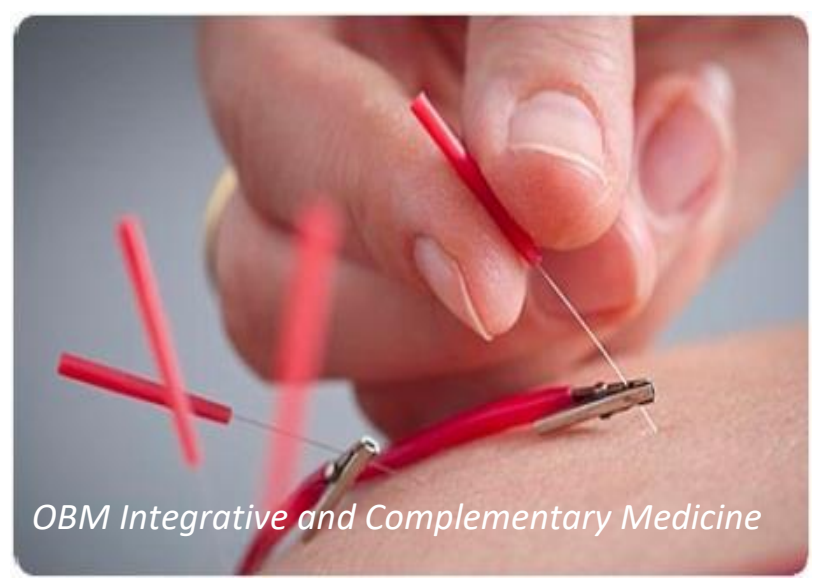

Enjoy OBM Integrative and Complementary Medicine by:

1. Submitting a manuscript

2. Joining in volunteer reviewer bank

3. Joining Editorial Board

4. Guest editing a special issue

For more details, please visit:

http://www.lidsen.com/journals/icm 